\title{
Factors Affecting Esthetics and Design of the Smile. A Review
}

\author{
Nahed A. Khalil \\ Professor, Dental Anatomy and Oral Histology Division, Oral Diagnostic Sciences Dept., Faculty of \\ Dentistry, King Abdul-Aziz University Jeddah, Saudi Arabia and Faculty of Oral and Dental \\ Medicine, Cairo University, Egypt.
}

Received: 10 Oct. 2019 / Accepted 15 Dec. 2019 / Publication date: 25 Dec. 2019

\begin{abstract}
The appearance of a human being is of important and great value in his life and society. The patients expectations are always high in getting beautiful and attractive smiles. Hence, the dentists have to do their best to fulfill these expectations as far as they can. Nowadays, the great advancement of dental materials and the introduced new techniques enable the dentists to provide wide varieties of treatment options to restore and improve the patients smile with an esthetic concern. Smiling has been one of the areas that draw the interest of the majority of dental specialties .In order to achieve a proper design of an attractive esthetic smile, it should be well understood what an ideal smile is and what are the factors that can affect it. This should certainly be reflected on the required successful treatment plan. Thus, this review aims to survey the current state of knowledge about the factors affecting smile esthetics as well as smile analysis and design. Also, the analysis of the surrounding soft tissues actually plays an important role in achieving the required pleasant smile.
\end{abstract}

Keywords: Ideal Smile, Smile Line, Esthetics, Proportions, Smile Analysis, Smile Design.

\section{Introduction}

Dentistry with its several specialities has focused on both function and esthetics. Recently, both dentists and patients have emphasized on esthetic dentistry because the society gives a high value to a person's appearance. Because of this obvious change in perception, the dental practice has completely changed from just restoring carious teeth to treating healthy teeth and creating an esthetic smile. Therefore, esthetics should be defined as the patient's perception of "visually pleasing or satisfying" and the clinician's experience in assessment of acceptable anatomic architecture coupled with proper function of the masticatory system (Brisman, 1980). A beautiful and attractive smile is among the important targets of dental treatment and is provided with an ideal smile line. Smile is affected by certain factors in addition to ideal smile line, such as buccal corridors, gingival display, arch width, tooth shapes, asymmetries, and age (Frush \& Fisher, 1958 and Tu“ zgiray \& Kaya, 2013). Esthetic dentistry is focusing to modify the teeth with pleasing proportions and their well arrangement in harmony with the surrounding soft tissues. A smile analysis, thus determines the proper esthetic appearance of the smile in relation to the facial symmetry, lip line and phonetics. Smile design is thus, the application of smile analysis to bring one's true potential into reality (Malarvizhi et al, 2017). Advancements in technology and availability of newer and better restorative materials have allowed meeting this new demand in improving the smile of the patient. Hence, this review article may cast light on the factors affecting smile esthetics as well as smile analysis and design.

\section{What is An Ideal Smile?}

Esthetic dentistry aims at two significant targets including well arrangement of teeth and beautiful smile. A beautiful and attractive smile is provided with an ideal smile line. The latter is the relation between the curvature of the incisal edge of the maxillary anterior teeth and that of the upper edge of the lower lip which should be parallel to each other (Frush and Fisher, 1958). This paralisem is known as the prerequisite for a "consonant" smile. However, if the maxillary incisors' incisal edge curvature is flatter than the lower lip's upper edge curvature during smiling, this smile is called "nonconsonant." Another prerequisite for a consonant smile is that maxillary incisors should be entirely visible during smiling (Wong et al., 2005). Maulik and Nanda, (2007) from the dynamic

Corresponding Author: Nahed A. Khalil, Dental Anatomy and Oral Histology Division, Oral Diagnostic Sciences Dept., Faculty of Dentistry, King Abdul-Aziz University Jeddah, Saudi Arabia and Faculty of Oral and Dental Medicine, Cairo University, Egypt. E-mail: nkhleel@kau.edu.sa - khalilnahed@live.com 
records, concluded that the smile line did not get flatter as it was expected, it got even more parallel to the lower lip curvature in orthodontically treated young adults. In an ideal smile, besides this parallel alignment, minimum buccal corridors and gingival display should be provided, first molar teeth should not be visible, and the width between the upper canines should be equal to the nose width (Hulsey, 1970 and Murakami et al., 2008).

\section{FACTORS AFFECTING AN IDEAL SMILE:}

\section{Buccal Corridors}

One of the factors that affect the smile is the buccal corridors which are the spaces between buccal surfaces of posterior teeth and lip corners. Several studies have been undertaken to specify the factors affecting the buccal corridor width and the relationship between their presence and smile esthetics (Moore et al., 2005; Parekh et al., 2006 and Martin et al., 2007). Yang et al. (2008) examined buccal corridor width on dental models, lateral cephalograms, and smile photograph and they detected no difference between extraction and non-extraction treatments. However, the vertical growth pattern of the face, visible amount of the upper incisors, and the total size of the tooth material affected the buccal corridor width. Maulik and Nanda, (2007) studied the dynamic smile in young adults and detected diminishing in the buccal corridors with rapid maxillary expansion treatment. It has been reported that the presence of minimum buccal corridors was found more attractive in both men and women, and the presence of buccal corridors was listed among orthodontic problems (Moore et al., 2005). Also, Martin et al. (2007) reported that both non specialists and orthodontists preferred narrow buccal corridors to wider ones. Orthodontists preferred tooth display between first molars while nonspecialists found tooth display between second premolars more attractive. Unlike nonspecialists, orthodontists marked asymmetric smiles as less attractive than symmetric smiles. Parekh et al. (2006) reported that the parallel smile line to the lower lip and the minimum buccal corridors appeared more attractive in men and women. Accordingly, the smile line should not be flatter with orthodontic treatment. However, it was concluded that flattening of the smile line reduced the undesired unesthetic effects of wide buccal corridors. Ioi et al., (2009a) in their study on orthodontists and dentistry students, preferred wide smiles with narrow buccal corridors over narrowand medium-grade smiles with wide buccal corridors. In another study on Korean and Japanese dentistry students, Ioi et al., (2009b) preferred wide smiles over narrow- and medium grade smiles.

On the other hand, Ritter et al. (2006) reported that these negative spaces did not affect esthetic evaluation in smile photographs. Also, Roden-Johnson et al. (2005) concluded that the presence of buccal corridors did not affect smile esthetics in their study on both orthodontists and nonspecialists.

\section{Gingival Display}

Gingival display is one of the factors that affect the smile. The increase of gingival display is called "gummy smile" which is an undesired condition in an ideal smile. This condition might result from vertical overgrowth of the maxilla, increase in overjet and overbite, and short length of the upper lip or incisor crowns (Allen, 1988). However, Peck and Kataja, (1992) and Peck et al., (1992) reported that the length of the upper lip and crown length of incisors did not affect "gummy smile". Polo, 2008 in his neuromuscular correction trial concluded that symmetrical labial Botox injections can be highly effective in the correction of "gummy smile" cases by inducing hyperfunction of the muscles contracting the upper lip upward during smiling. However, it should be kept in mind that a certain part of the effect is temporary. Several studies were conducted to evaluate the relation between the gingival display and smile esthetics (Hunt et al., 2002; Geron \& Atalia, 2005 and Ioi et al., 2010).

Ioi et al., (2010) investigated that by surveying the opinions of orthodontists versus dentistry students as well as male versus female participants. The authors found the gingival display varied between $-5 \mathrm{~mm}$ and $+5 \mathrm{~mm}$ in the evaluated smile photographs. While no difference was obtained between male and female participants, certain differences were noted between the opinions of orthodontists and dentistry students. The students appeared to be less tolerant concerning "gummy smile". While orthodontists found $0 \mathrm{~mm}$ gingival display the most attractive, dentistry students found the smile in which the lip covered the upper incisor teeth by $2 \mathrm{~mm}$ the most attractive.

Hunt et al., (2002) conducted his study on nonspecialists and the visible amount of gingiva varied between $-2 \mathrm{~mm}$ and $+4 \mathrm{~mm}$ in the photographs they used. The results showed that the smiles 
with complete incisors visibility and $0 \mathrm{~mm}$ gingival visibility were considered the most attractive ones. The smiles in which the gum was visible by more than $2 \mathrm{~mm}$ were classified as less attractive. Geron and Atalia, (2005) concluded that gingival display was considered esthetic at $0 \mathrm{~mm}$ in the lower incisors and up to $1 \mathrm{~mm}$ in the upper incisors. Asymmetric inclinations up to $2 \mathrm{~mm}$ on the incisal plane were considered esthetic. Female participants gave higher points for gingival display in maxillary incisors and they appeared to be more tolerant to gingival display.

\section{Arch Width}

Several studies have been undertaken to investigate the effect of the arch width on the smile esthetics in extraction and non-extraction orthodontic treatments (Witzig \& Spahl, 1987; Dierkes, 1987; Johnson \& Smith, 1995; Kim \& Gianelly, 2003 and Isxıksal, 2006). Witzig and Spahl, (1987) and Dierkes, (1987) claimed that dental arches get diminshed in extraction cases and thus, the smile esthetics reduces. However, Johnson and Smith, (1995) reported that dental view during smile and smile esthetics are similar in extraction and nonextraction treatment patients. Also, Kim and Gianelly, (2003) evaluated dental models and frontal photographs in extraction and nonextraction orthodontic treatment patients. They concluded that reduction of dental arches was not a routine result of extraction treatments and thus, neither extraction nor nonextraction orthodontic treatments affected the smile esthetics.

Roden-Johnson et al., (2005) also evaluated the effect of the arch form on smile esthetics and obtained differences between groups. While dentists found smiles with wide arches more attractive than smiles of individuals who did not receive treatment, orthodontists found the smiles of individuals with wide arches more attractive than those who had narrow arches and did not receive treatment. Non specialists, in contrast, did not prefer any of these arch forms. In addition, Isxiksal et al., (2006) evaluated smile esthetics in orthodonticaly and non orthodonticaly treated individuals. The study involved 25 extraction orthodontic treatment patients, 25 non extraction orthodontic treatment patients, and 25 individuals with ideal occlusion who did not receive any orthodontic treatment and evaluated opinions of orthodontists, plastic surgeons, artists, dentists, and parents of patients. They obtained no difference between the non orthodonically treated individuals with their ideal occlusion and those with Class 1relation by receiving extraction or nonextraction treatment in terms of smile esthetics. They indicated that the transversal character of smile has little effect on attraction. However, they reported that maxillary gingival display and anterior teeth positions have an important effect on smile esthetics.

\section{Tooth Shape}

Some investigators have correlated the tooth shape and smile esthetics. Williams, 1914 indicated that the tooth shape should be evaluated along with the facial form. However, others did not find any correlation between a present or artificial tooth shape and the form of the face (Brodbelt et al., 1984; Bell, 1987 and Seluk et al., 1987). In the past, it was suggested the use of soft edged, round-shaped teeth for women and angled, square-shaped teeth for men (Frush \& Fisher, 1955 and Marunick, 1983), which is limited today. Anderson et al., (2005) surveyed the opinions of restorative dentists, orthodontists, and nonspecialists concerning tooth shape and esthetics. Orthodontists found the smiles of women with round and round-square formed incisors more attractive, and restorative dentists preferred those with round incisors, while the nonspecialists did not distinguish between the incisor forms. In men, all 3 groups found the smiles with square-round formed incisors more esthetic. At the same time, independent of the tooth form, all 3 groups found the smiles of female patients more attractive than those of males.

\section{Asymmetries}

Dental asymmetries appeared to affect the smile esthetics negatively. However, studies in this field are limited. Pinho et al., (2007) depending on the opinions of orthodontists, prosthodontists, and nonspecialists, evaluated the effect of asymmetry of the maxillary incisor in the gingival margin of the tooth, asymmetry due to wear of the cusp tip of the canine, and asymmetry due to dental midline shift on smile esthetics. Differences were obtained, and while orthodontists and prosthodontists indicated that the asymmetry of $0.5 \mathrm{~mm}$ in the gingival margin of the maxillary incisor affected the smile esthetics, this value was $2 \mathrm{~mm}$ for nonspecialist individuals. All 3 groups decided that wear of the 
cusp tip of the maxillary canine did not affect the smile esthetics. For the dental midline shift, orthodontists indicated that $1 \mathrm{~mm}$ or higher values negatively affected the smile esthetics, and prosthodontists indicated that $3 \mathrm{~mm}$ or higher values negatively affected the smile esthetics. Nonspecialists did not distinguish the dental midline shift. According to the difference between the opinions of the groups, it was concluded that the patient's opinion should also be taken into consideration in the treatment planning.

\section{Age}

The effect of age and the resultant mouth and facial changes on the smile esthetics was studied by Geld et al., (2008). The authors examined the upper and lower lips in individuals from 3 different age groups (20-25 years, 35-40 years, and 50-55 years) at rest position, during spontaneous smiling, and during speech with the digital videography. They reported that the height of the maxillary lip line was reduced in both cases, and this decrease was about $2 \mathrm{~mm}$ in spontaneous smile. The lip line height was measured as the visible gingival height in the anterior maxilla during smile, speech, or at rest position. Also, they reported an increase in mandibular incisor display at rest position, increase in the upper lip length by $4 \mathrm{~mm}$, and thus, decrease in the maxillary teeth display during smiling. Hence, it can be concluded that smile esthetics is negatively affected by aging and that esthetic dental treatment should be planned by taking the changes brought by aging into consideration.

Desai et al., (2009) examined the effects of aging with the digital videography method and they evaluated the upper lip length and upper lip width during smile and at rest, maxillary incisor display and the amount of interlabial space during smile, presence of buccal corridors, the distance between the commissures at rest, the smile height, the smile line, and the smile index. They carried out these examinations on 5 groups separated by age range (15-19 years, 20-29 years, 30-39 years, 40-49 years, 50 years and over). They found diminishing in the maxillary incisor display by about $1.5-2 \mathrm{~mm}$ by increased age. Again depending on aging, the smile index (the distance between the commissures during smile/interlabial space) increased significantly; in other words, the smile reduced vertically and increased transversally. No one at 50 years of age or over had a high smile, and none of the participants from the age group of 15-19 years was found to have low smile. According to all dynamic measurements in this study, it can be concluded that sufficiency of the muscles that allow the smile diminishes by advancement of age.

\section{FACTORS AFFECTING SMILE DESIGN:}

\section{Prenciples in Smile Design Theory}

Malarvizhi et al., (2017) identified four important principles in designing a smile, including, facial esthetics, gingival esthetics, micro esthetics and macro esthetics. Facial esthetics involves the facial and muscular considerations which is determined through photographs taken before and after treatment. Gingival esthetics means the gingival health and appearance. Microesthetics involves the specific anatomy of each tooth with consideration to the specific incisal translucency, characterization, lobe development and incisal haloing. Macroesthetics is the relationship of the teeth to the surrounding soft tissue and patient's facial characteristics. Also, the authors suggested various proportions which aids in smile analysis before establishing the treatment plan.

\section{Divine Proportion}

Pythagoras in $530 \mathrm{BC}$ proposed the golden number, represented by the Greek symbol $\Delta$ The reciprocal of $\Delta$ is 0.618 and is termed as the Golden or Divine proportion (Gillen et al., 1994). It was believed that the objects whose features conform to this ratio were perceived to have innate beauty. If all the objects conform to this ratio, we would be surrounded by clones. Hence, repeated or recurring ratios are more significant than a specific ratio.

\section{Dental Proportions}

It has been reported that the height of the central incisor should be 1/16 the height of the face from ideal hairline to the chin and its width should be 1/16 the interzygomatic width (Oschsenbein and Ross,1999). 


\section{Golden Proportion}

The golden proportion has been used to relate the successive widths of the anterior teeth as seen from the front. The width of the central incisor should be multiplied by the value defined as the golden proportion, which is 0.618 , or approximately $62 \%$. The resultant width of the lateral incisor should be multiplied by $62 \%$ to give the width of the canine (Figure 1,2) (Levin, 2005).

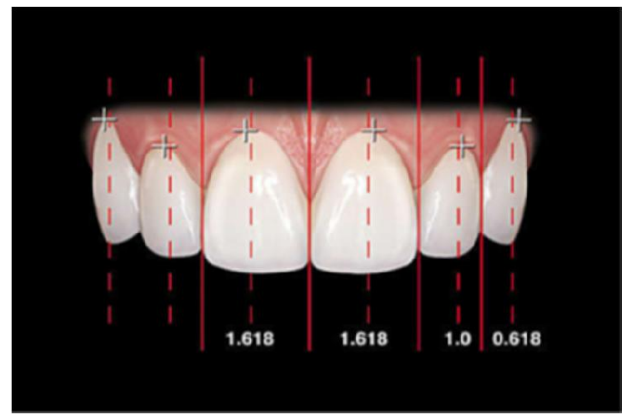

Fig. 1: Golden proportion

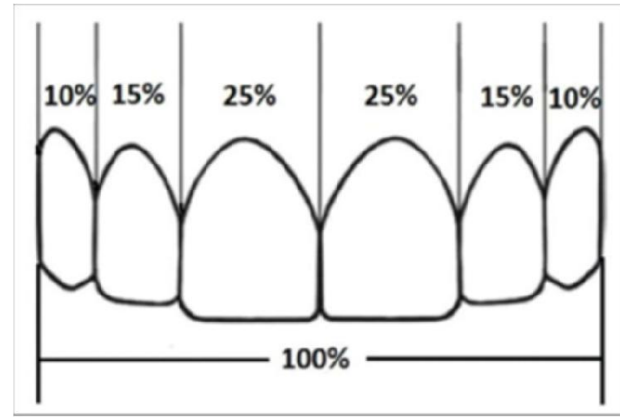

Fig. 2: Golden percentage

\section{Repeated Ratio}

The use of a "continuous proportion or repeated ratio has been suggested and established between the width of central and lateral incisor and continued in the ratio of the placement of the remaining teeth and spaces." The proportion of the width of the central incisor and the lateral incisor should be consistent between the width of the lateral incisor and the canine and from the canine to the first premolar moving distally. The ratio between the width of the central incisor and the lateral incisor should be applied consistently to define the desired ratio between the lateral incisor and the canine (Lombardi, 1973).

\section{Recurring Esthetic Dental (RED) Proportion}

The RED proportion states that the proportion of the successive widths of the teeth as seen from the frontal view should remain constant as one move distally. Instead of accepting the proportion already defined by the widths of the central and lateral incisors, the dentist can define his or her desired RED proportion which gives greater flexibility (Lombardi, 1973; Wagner et al., 1996).

\section{Width - to -Height Ratio}

An important proportion that has to be evaluated is the width-to-height ratio of the central incisor which has been preferred to be in the range of $66 \%-80 \%$ (Mathews, 1997).

\section{Facial Image View Evaluation (FIVE)}

The use of a photograph to evaluate and measure the relative teeth dimensions and proportions in a smile is called Facial Image View Evaluation (FIVE). An image taken parallel to the facial plane and at least 8 inches away from the teeth should be used to minimize distortion. A common dimension of a central incisor is measured first on the photograph and then on the cast (Silnes, 1980). The cast dimension is divided by the image dimension to compute a conversion factor, which correlates the size of the image to the actual size of the teeth. The height of the central incisor is preferred, but the width can be used if the gingival margin is not totally visible. The photographic image widths and heights of the anterior 6 teeth are measured and recorded. The photographic measurements are multiplied by the conversion factor to give the FIVE dimensions. It was found that the further distal the dentist moves, the greater is the discrepancy between the FIVE and the cast dimensions.

\section{Red Smile Design}

The ideal width and height of a central incisor can be determined using the equation $\{($ FIVE width of the anterior 6 teeth $) / 2(1+$ RED + RED2 $)\}=$ width of central incisor (The RED should be expressed as a decimal $<1$ ) (Width of central incisor $/$ Width-to-height ratio) $=$ height of central incisor 
(The width-to-height ratio should be expressed as a decimal <1) (Levin, 1997).

\section{Smile Evaluation}

To evaluate the smile, static records, dynamic records, and records of direct biometric measurements are obtained before the beginning of treatment. Static records involve routinely taken intraoral and extraoral photographs. The latter includes the frontal view at rest position, frontal smile view, and profile view at rest position (Janzen, 1977). Although these static views are sufficient for diagnostic evaluation, they are not sufficient for display and quantitative evaluation of the smile. Therefore, the more advanced techniques of dynamic records are required and obtained by digital videography method, while direct biometric measurements are made on close-up smile photographs (Sarver and Ackerman, 2003). The authors suggested a standard of 3 extraoral photographs for a better smile evaluation including smile from profile, $3 / 4$ smile, close-up frontal smile, and close-up $3 / 4$ smile.

The "smile index" value could be calculated from the close-up frontal smile photograph by dividing the distance between the commissures by the interlabial distance in the smile. It allows detecting the age-dependent smile changes in the same patient or comparing smiles in different patients (Ackerman et al., 1998 and Ackerman, 2003).

Tarantili et al., (2005) evaluated spontaneous smile dynamically and indicated that a single photograph could not be sufficient in esthetic evaluation and orthodontic treatment planning. However, Schabel et al., (2010) reported that digital videography provided too much information in evaluation of the dynamic characteristic of the smile, but the standard digital photography method was still sufficient for evaluation of the smile after treatment. Dynamic records of smile and speech by digital video and computer technology allows taking 30 views per second. Sarver and Ackerman, (2003) reported that taking 5-second videos from patients at the beginning and at the end of treatment is sufficient. They suggested that saying "Chelsea eats cheesecake on the Chesapeake" in English and smiling thereafter during video recording. It is indicated that it is possible to evaluate smiles by selecting the view that is the closest to natural smile from the patient's video (Ackerman et al., 1998).

McNamara et al., (2008) evaluated soft and hard tissue factors that affected esthetics with the digital videography method in growing patients. They concluded that the vertical width of the lips is considered the most important factor affecting a beautiful smile and the vertical width of the upper lip is determined by the position of the maxillary incisor. Dynamic digital video clips also allow the classification of the smile into 3 types. The first is called "commissure smile" or "Mona Lisa smile," in which the patient's lip corners move upward depending on the contraction of the zygomaticus major muscle. The second one is called "canine smile," with the entire upper lip moves upward with smiling. The third type is called "complex smile" in which both upper and lower lips move upward and downward respectively (Rubin, 1974).

On the other hand, direct biometric measurements are millimetric measurements on a close-up smile photograph that allow the clinician to evaluate the lip-tooth relationship. This evaluation is important when reflected in the orthodontic treatment plan. Also, it allows the evaluation of age dependent changes and repeatability of the smile with these measurements. Philtrum and commissure height, distance between lips at rest, visible amount of incisors at rest and while smiling, crown height and gingival display can be calculated with direct biometric measurements (Sarver and Ackerman, 2003). Among them, maxillary incisor display at rest position is a highly important parameter. Subtelny, (1959) reported that if a patient has 3-mm gingival display while smiling or 3-mm incisor display at rest, intrusion of maxillary incisors is necessary.

Thus, the following features should be analyzed to determine the relationship of teeth to the surrounding soft tissues.

\section{Smile Line}

Three types have been identified for the smile line, namely, low, average and high according to the amount of upper anterior teeth exposure during smiling (Tjan and Miller, 1984). Low smile line is the one when there is no more than $75 \%$ exposure of anterior teeth, average smile line is that when there is $75-100 \%$ exposure of anterior teeth and interproximal papillae, whereas high smile line is that when there is complete exposure of anterior teeth along with gingival display (Figure 3). Excessive 
gingival display (more than $3 \mathrm{~mm}$ ) is not an ideal smile. A smile is considered esthetic only when there is exposure of anterior teeth along with approximately $1 \mathrm{~mm}$ of gingival tissue (Allen, 1988).

\section{Interincisal Line vs. Midline}

The interdental papillae between the maxillary central incisors is considered the most reliable reference point for determining the midline which should be in one line with the middle of the philtrum and nose. When doing restoration for anterior teeth, position of the midline is considered (Figure 4) (Kokich, 1993).

\section{Smile Width}

The amount of exposure of the anterior teeth during smiling due to movement of lips should be determined. In patients with wider smile, restorations even in the posterior region should be conservative and esthetic (composite or ceramic).

\section{Analysis of Gingival Tissues}

Symmetry of gingival margins has an important role in esthetic dentistry (Kois, 1994). The gingival margins of maxillary lateral incisors should be in a coronal position compared to that of maxillary central incisors and canines. Orthodontic correction may be required in some cases. If there is slight disharmony, it can be corrected with gingivectomy.

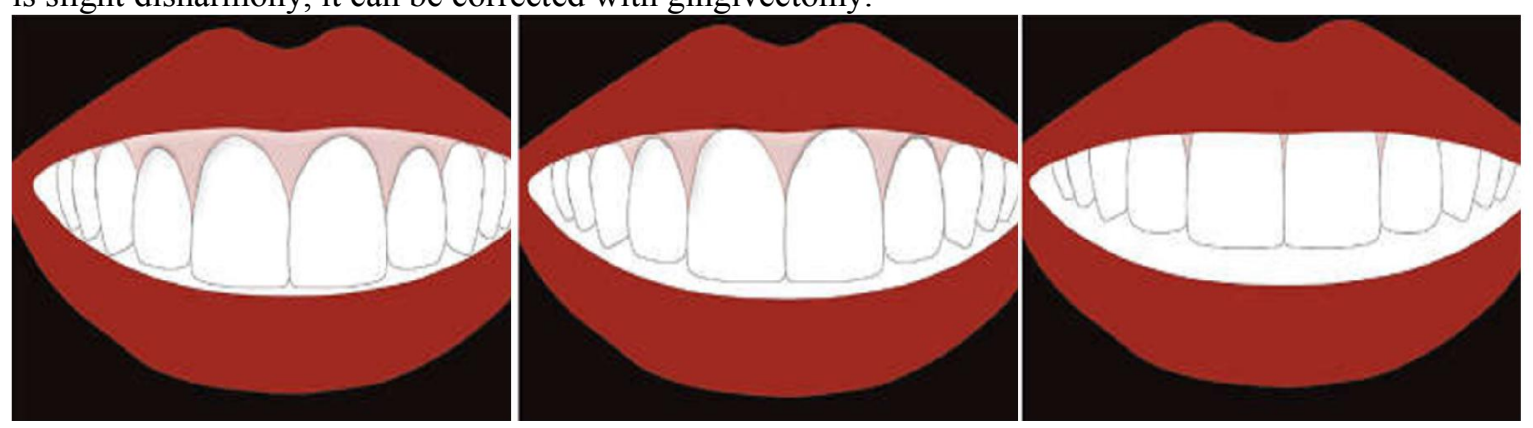

Fig. 3 : Smile Line

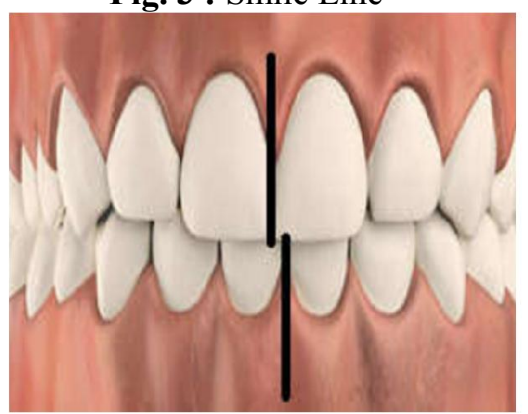

Fig. 4: Interincisal vs midline

\section{Esthetics and Function}

Achieving esthetics with a compromise on the functional component is no longer considered ideal. Esthetic appearance in conjunction with appropriate function is the objective of esthetic dentistry (Pietrobon and Paul, 1997). Whenever esthetic treatment is planned, a proper case history should be taken to get an idea on patients' expectations. Thorough clinical examination along with radiographs and photos will help the clinician to have a proper knowledge on the current clinical condition. Interdisciplinary approach would enhance the appearance of esthetic smile. Psychological status of the patient should also be evaluated before instituting any procedure.

\section{Conclusion}

Smile esthetics proved to be affected by several factors including the width of buccal corridors, gingival display, arch width, tooth shape, dental asymmetries, and age. These findings indicate that providing a good functional occlusion is not sufficient alone to obtain satisfactory results with 
different dental specialities including orthodontic treatments. Careful evaluation and rational approach by the dentist would help to analyze the harmony of dental and facial tissues to the surrounding soft tissue and to achieve an esthetically pleasing smile without a functional compromise. Consequently, it is necessary to provide smile esthetics that is appreciated by the patients much more today and to include the factors affecting smile esthetics and design in different treatment planning accordingly.

\section{References}

Ackerman, J.L., M.B. Ackerman, C.M. Bresinger, and J.R. Landis, 1998. A morphometric analysis of the posed smile. Clin. Orthod Res., 1:2-11.

Ackerman, M.B., 2003. Digital video as a clinical tool in orthodontics: dynamic smile design in diagnosis and treatment planning. 29 ${ }^{\text {th }}$ Annual Moyer's Symposium. Vol 40. Ann. Arbor., Mich: University of Michigan Department of Orthodontics.

Allen, E.P., 1988. Use of mucogingival surgical procedures to enhance esthetics. Dent. . Clin. North Am., 32:307-330.

Anderson, K.M., R.G. Behrents, T.M.C. Kinney, and P.H. Buschang, 2005. Tooth shape preferences in an esthetic smile. Am. J. Orthod Dentofacial Orthop., 128:458-465.

Bell, R.A., 1978. The geometric theory of selection of artificial teeth. J Am Dent Assoc., 97:637-640.

Brisman, A.S., 1980. Esthetics: a comparison of dentists and patients concepts. J Am Dent Assoc. 100: $345-52$.

Brodbelt, R.H.W., G.F. Walker, D. Nelson, and L.W. Seluk, 1984. A comparison of tooth shape with tooth form. J. Prosthet. Dent., 52:588-592.

Desai, S., M. Upadhyay, and R. Nanda., 2009. Dynamic smile analysis: changes with age. Am J Orthod Dentofacial Orthop., 136:310.e1-310.e10.

Dierkes, J.M., 1987. The beauty of the face: an orthodontic perspective. J Am Dent Assoc., 89E-95E.

Frush, J.P., and R.D. Fisher, 1955. Introduction to dentogenic restoration. J Prosthet Dent., 5:586595.

Frush, J.O., and R.D. Fisher., 1958. The dyesthetic interpretation of the dentogenic concept. J. Prosthet. Dent., 8:558.

Geld, P.V., P. O. Osterveld, and A.M. Kuijpers-Jagtman, 2008. Age-related changes of the dental aesthetic zone at rest and during spontaneous smiling and speech. Eur. J. Orthod., 30: 366-373.

Geron, S., and W. Atalia, 2005. Influence of sex on the perception of oral and smile esthetics with different gingival display and incisal plane inclination. Angle Orthod., 75:778-784.

Gillen, R. J., R. S. Schwartz, T. J. Hilton, and D. B. Evans, 1994. An analysis of selected normative tooth proportions. Int. J. Prosthodont., 7:410-7.

Hulsey, C.M., 1970. An esthetic evaluation of lip-teeth relationships present in the smile. Am. J. Orthod., 57:132-144.

Hunt, O., C. Johnston, P. Hepper, D. Burden, and M. Stevenson, 2002. The influence of maxillary gingival exposure on dental attractiveness ratings. Eur. J. Orthod., 24:199-204.

Ioi, H., S. Nakata, and A.L. Counts, 2009a. Effects of buccal corridors on smile esthetics in Japanese. Angle Orthod., 79:628-633.

Ioi, H., S. Nakata, and A.L. Counts, 2009b. Comparison of the influences of buccal corridors on smile esthetics between Koreans and Japanese. Orthod. Waves, 68:166-170.

Ioi, H., S. Nakata, and A. L. Counts, 2010. Influence of gingival display on smile aesthetics in Japanese. Eur. J. Orthod. 2010; 32: 633-637.

Isxıksal, E., H. Serpil, and S. Akyalc, 2006. Smile esthetics: perception and comparison of treated and untreated smiles. Am. J. Orthod Dentofacial Orthop., 129:8-16.

Janzen, E., 1977. A balanced smile_-a most important treatment objective. Am J Orthd., 72:359-372.

Johnson, D.K., and R.J. Smith, 1995. Smile esthetics after orthodontic treatment with and without extraction of four first premolars, Am. J. Orthod. Dentofacial Orthop., 108:162-167.

Kim, E., and A.A. Gianelly, 2003. Extraction vs nonextraction: arch widths and smile esthetics. Angle Orthod., 73:354-358.

Kois, J.C., 1994. Altering gingival levels: The restorative connection Part 1: Biologic variables J Esthet Dent., 6: 3-9. 
Kokich, V., 1993. Esthetics and anterior tooth position: an orthodontic perspective, part II: vertical position. J. Esthet. Dent., 5(4):174-8.

Levin, E.I., 1997. Dental esthetics and the golden proportion. J. Prosthet. Dent., 40: 244-52.

Levin., 2005. The golden proportion. J. Prosthet. Dent., 40: 244-252.

Lombardi, R.E., 1973. The principles of visual perception and their clinical application to denture esthetics. J. Prosthet, Dent., 29:358-82.

Malarvizhi, D., K. Arumugam, R. Mensudar, N.S.G.P. New Begin, Mary, and N. Geethapriya, 2017. Factors affecting smile design - A Review, International Journal of Current Research, 9 (10): 59830-59833.

Martin, A.J., P.H. Bushang, J.C. Boley, R.W. Taylor, and T.W. McKinney, 2007. The impact of buccal corridors on smile attractiveness. Eur. J. Orthod. 29:530-537.

Marunick, M.T., B.B. Chamberlain, and C.A. Robison, 1983. Denture esthetics: an evaluation of layman's preferences. J. Oral Rehabil, 10:399-406.

Mathews, T.G., 1997. The anatomy of a smile. J. Prosthet. Dent., 39; 39-44.

Maulik, C., and R. Nanda, 2007. Dynamic smile analysis in young adults. Am. J. Orthod Dentofacial Orthop., 132:307-315.

McNamara, L., J.A. McNamara, M.B. Ackerman, and T. Baccetti, 2008. Hard and soft tissue contributions to the esthetics of theposed smile in growing patients seeking orthodontic treatment. Am. J. Orthod. Dentofacial. Orthop., 133: 491-499.

Moore, T., K.A. Southard, J.S. Casko, F. Qian, and T.E. Southard., 2005. Buccal corridors and smile esthetics. Am. J. Orthod. Dentofacial Orthop., 127:208-213.

Murakami, Y., T.S.R. Deguchi, T. Kageyama, H. Miyazawa, and K. W.C. Foong, 2008. Assessment of the esthetic smile in young Japanese women. Orthod. Waves, 67:104-112.

Oschsenbein, C., and S. Ross, 1999. A reevaluation of osseous surgery. Dent. Clin. North Am., 13: 87-102.

Parekh, S.M., H.W. Fields, M. Beck, and S. Rosenstiel, 2006. Attractiveness of variations in the smile arch and buccal corridor space as judged by orthodontists and laymen. Angle Orthod., 76:557563.

Peck, S.M. Kataja, 1992. Some vertical lineaments of lip position. Am. J. Orthod. Dentofacial Orthop. 101:519-524.

Peck, S., L. Peck and M. Kataja, 1992. The gingival smile line. Angle Orthod., 62:91-100.

Pietrobon, N., S. Paul, 1997. All ceramic restorations: A Challenge for anterior esthetics. J Esthet Dent., 9: 179-186.

Pinho, S., A. Ciriaco, J. Faber, and M.A. Lenza, 2007. Impact of dentalasymmetries on the perception of smile esthetics. Am. J. Orthod. Dentofacial. Orthop., 132:748-753.

Polo, M., 2008. Botulinum toxin type A (Botox) for the neuromuscular correction of excessive gingival display on smiling (gummy smile). Am. J. Orthod. Dentofacial Orthop., 133: 195-203.

Ritter, D.E., L.G. JR Gandini, A. D. S. Pinto, and A. Locks, 2006. Esthetic influence of negative space in the buccal corridor during smiling. Angle Orthod., 76:198-203.

Roden-Johnson, D., R. Gallerano, and J. English, 2005. The effects of buccal corridor spaces and arch form on smile esthetics. Am. J. Orthod. Dentofacial Orthop., 127:343-350.

Rubin, L. R., 1974. The anatomy of a smile: its importance in the treatment of facial paralysis. Plast Reconstr. Surg., 53:384-387.

Sarver, D.M., and M.B. Ackerman, 2003. Dynamics mile visualization and quantification: part 1. Evolution of the concept and dynamic records for smile capture. Am. J. Orthod. Dentofacial Orthop., 124:4-12.

Schabel, B.J., T. Baccetti, L. Franchi, and J. A. McNamara, 2010. Clinical photography vs digital video clips for the assessment of smile esthetics. Angle Orthod., 80:678-684.

Seluk, L., R. Brodbelt, and G. Walker, 1987. A biometric comparison of face shape with denture form. J. Oral Rehabil, 14:139-145.

Silnes, J. 1980. Fixed Prosthodontics and periodontal health. Dent Clin North Am; 24: 317-329.

Subtelny, J. D. A., 1959. Longitudinal study of soft tissue facial structures and their profile characteristics, defined in relation to underlying skeletal structures. Am. J. Orthod., 45: 481-507.

Tarantili, V. V., D. J. Halazonetis, and M. N. Spyropoulos, 2005. The spontaneous smile in dynamic motion. Am. J. Orthod. Dentofacial Orthop., 128:8-15. 
Tjan, A. H. L., and G.D. Miller, 1984. Some esthetic factors in a smile. J. Prosthet. Dent., 51: 24-28. Tü zgiray, Y.B., and B. Kaya, 2013. Factors affecting smile esthetics. Turkish J. Orthod., 26:58-64.

Wagner, I., G. Carlsson, K. Ekstrand, P. Odman, and N. Schneider, 1996. A comparative study of assessment of dental appearance by dentists, dental technicians and laymen using computer-aided image manipulation. J. Esthet. Dent., 8:199-205.

Williams, J. L., 1914. A new classification of human tooth forms with reference to a new system of artificial teeth. Dent. Cosmos., 56:627-628.

Witzig, J.W., and R. J. Spahl, 1987. The Clinical Management of Basic Maxillofacial Orthopedic Appliances. Littleton, Mass: PSG., Publishing; 1-13.

Wong, N. K. C., A. A. Kassim, and K.W.C. Foong, 2005. Analysis of esthetic smiles by using computer vision techniques. Am. J. Orthod. Dentofacial Orthop., 128:404-411.

Yang, I.H., D. S. Nahm, and S. H. Baek, 2008. Which hard and soft tissue factors relate with the amount of buccal corridor space during smiling? Angle Orthod., 78:5-11. 